\title{
PAPERS
}

\section{Dietary polyamines are essential luminal growth factors for small intestinal and colonic mucosal growth and development}

\author{
Chr Löser, A Eisel, D Harms, U R Fölsch
}

\begin{abstract}
Background-Polyamines are essential for cell growth. Dietary and probably gut bacterial derived polyamines contribute significantly to the polyamine body pool. Aims-To evaluate the influence of dietary, luminal polyamines on growth and development of different gastrointestinal organs in normally growing rats.

Methods-Male suckling Wistar rats were randomly allocated to four treatment groups: polyamine deficient diet (PDD); PDD plus antibiotics (neomycin $2 \mathrm{~g} / \mathrm{kg}$ and metronidazole $34 \mathrm{mg} / \mathrm{kg}$ ); PDD plus polyamine supplementation at normal concentrations; or normal standard laboratory chow. After a six month feeding period 7-10 animals/group were sacrificed. Results-No differences in body weight gain, food consumption, or general behaviour could be observed between the four groups of animals. Feeding of PDD alone or PDD plus antibiotics resulted in a highly significant decrease in organ weight, protein content, and DNA content in small intestinal and colonic mucosa whereas no alterations were found in the liver.

Conclusions-Long term feeding of polyamine deficient diets resulted in a significant hypoplasia of small intestinal and colonic mucosa. Dietary, luminal polyamines are important local factors for growth and the development of small intestinal and colonic mucosa.

(Gut 1999;44:12-16)
\end{abstract}

Medical Departme University,

Schittenhelmstrasse

12, D-24105 Kiel,

Germany

Chr Löser

A Eisel

U R Fölsch

Institute of Pathology, Christian-Albrechts-

University, Kiel,

Germany

D Harms

Correspondence to:

Professor Löser.

Accepted for publication 22 July 1998
Because of its high proliferation rate, intestinal and colonic mucosa has a special demand for polyamines. ${ }^{112}$ Uptake of extracellular polyamines via luminal or basolateral membrane either by distinct polyamine carriers ${ }^{13} 14$ or passive diffusion ${ }^{15} 16$ was found to be an important regulatory mechanism of polyamine metabolism during small intestinal and colonic adaptation. ${ }^{15-18}$ Oral administration of spermine or spermidine was able to induce precocious morphological and functional maturation of the small bowel and accelerated early intestinal development. ${ }^{19-21}$ On the other hand, deprivation of gastrointestinal polyamines by feeding polyamine deficient diets and reducing luminal polyamine producing bacteria by oral antibiotics caused a significant reduction in solid tumour proliferation and confirmed the relevance of luminal polyamines for malignant growth..$^{8-10} 22$

While the importance of luminal gastrointestinal polyamines for adaptive and malignant growth is well documented, little is known about their function in normal, physiological organ growth. The present study was designed to evaluate the long term effects of dietary and gut bacterial derived polyamines on growth and development of various gastrointestinal organ systems in normally growing rats.

\section{Materials and methods}

CHEMICALS

The following substances were purchased from Sigma Chemical Co. (St Louis, Missouri, USA): $o$-phthalaldehyde, 1,7-diaminoheptane and polyamine standards, Brij 35, bovine serum albumin, calf thymus DNA, sucrose, Tris buffer, dithiothreitol, pyridoxal phosphate, hyamine hydroxide, neomycin, metronidazole, and ammonium formate. Acetonitrile, glycerol (87\%), disodium phosphate, and phenylmethylsulphonyl fluoride were from Merck (Darmstadt, Germany). DL- $\left[1-{ }^{14} \mathrm{C}\right]$ ornithine, $S$-adenosyl-Lcarboxyl- ${ }^{14} \mathrm{C}$ methionine, $1-{ }^{14} \mathrm{C}$-acetyl CoA, and methyl- ${ }^{3} \mathrm{H}$-thymidine triphosphate were

Abbreviations used in this paper: $\mathrm{AB}$, antibiotics; ODC, ornithine decarboxylase; PA, polyamines; PDD, polyamine deficient diet; SAM-DC,

$S$-adenosylmethionine decarboxylase; SAT, spermidine/spermine $\mathrm{N}$-acetyltransferase. 
obtained from Amersham (Little Chalfont, UK). Millex-GS-filters, pore size $0.22 \mathrm{~mm}$, were from Millipore (Molsheim, France). Whatman glass fibre filters $(\mathrm{GF} / \mathrm{C})$ and Whatman $\mathrm{DE} 81$ ion exchange filters were from Whatman International (Maidstone, UK). Bisbenzimidazole (Hoechst H-33258) was from Hoechst (Frankfurt, Germany) and Bio-Rad protein reagent was purchased from Bio-Rad Laboratories (Munich, Germany).

DIETS

Standard laboratory chow as well as the different special diets were obtained from Altromin (Lage/Lippe, Germany). Polyamine deficient diet (PDD), polyamine deficient diet plus antibiotics (neomycin $2 \mathrm{~g} / \mathrm{kg}$ and metronidazole 34 $\mathrm{mg} / \mathrm{kg}$ ) (PDD + $\mathrm{AB}$ ), as well as polyamine deficient diet plus normal, physiological supplementation with polyamines (putrescine 80 $\mathrm{mg} / \mathrm{kg}$, spermidine $300 \mathrm{mg} / \mathrm{kg}$, spermine 100 $\mathrm{mg} / \mathrm{kg})(\mathrm{PDD}+\mathrm{PA})$ were identically prepared as previously published by Seiler and colleagues $^{9}$ and Sarhan et al. ${ }^{22}$ The polyamine deficient diets used in this study were fully balanced, well tolerated animal diets. ${ }^{92}$ HPLC analysis revealed a putrescine, cadaverine, and spermine content below the detection limit of the method; spermidine content was less than $15 \mathrm{nmol} / \mathrm{g}$ diet which is a reduction of more than $98 \%$ compared with standard laboratory chow $(560 \mathrm{nmol} / \mathrm{g})$.

ANIMALS

Male suckling Wistar rats (30-40 g, Harlan Winkelmann, Borcken, Germany) were housed at $24^{\circ} \mathrm{C}$ and exposed to a 12 hour light/ 12 hour dark cycle. Animals had free access to water and food. Water and food consumption as well as body weight were registered once a week for 24 hours. The study was approved by the Board of Ethics of the Christian-Albrechts University of Kiel, Germany.

EXPERIMENTAL DESIGN

Male suckling Wistar rats were randomly allocated directly after weaning into one of four different treatment groups: (1) polyamine deficient diet (PDD); (2) polyamine deficient diet plus antibiotics (PDD + AB); (3) polyamine deficient diet plus supplementation with putrescine, spermidine, and spermine at physiological concentrations (PDD + PA); and (4) normal standard laboratory chow. Once a week the following parameters were registered: body weight, water and food consumption, animal behaviour, and stool characteristics. After a six month feeding period 7-10 animals/group were killed and the following parameters were analysed in small intestine, colon, and liver: organ wet weight; single blinded, detailed histological analysis of all organs by a skilled pathologist (DH); protein and DNA content; DNA polymerase activity; polyamine concentrations; and activities of ornithine decarboxylase (ODC), S-adenosylmethionine decarboxylase (SAM-DC), and spermidine/spermine N'acetyltransferase (SAT). For statistical analysis the PDD + PA fed animals are regarded as the control group.
ANALYTICAL PROCEDURE

Homogenisation

The whole small intestine, colon, and liver were removed and homogenised 1:5 on ice, firstly in a buffer solution consisting of $10 \mathrm{mM}$ Tris buffer ( $\mathrm{pH} 7.9$ ), $25 \mathrm{mM} \mathrm{KCl}, 5 \mathrm{mM} \mathrm{MgCl}_{2}$, $0.25 \mathrm{M}$ sucrose, $5 \mathrm{mM}$ dithiothreitol, and 1 $\mathrm{mM}$ phenylmethylsulphonyl fluoride with a Potter S homogeniser at $1000 \mathrm{rpm}$ (Braun, Melsungen, Germany; 10 up and down strokes) and then with a Dounce glass/glass homogeniser (Kontes Glass, Vineland, New Jersey, USA; 15 up and down strokes). Aliquots were taken and stored at $-20^{\circ} \mathrm{C}$ until required for DNA protein and polyamine analyses. The remainder of the raw homogenate was centrifuged at $1000 \mathrm{~g}$ for 10 minutes; the supernatant was removed and ultracentrifuged at $110000 \mathrm{~g}$ $\left(2^{\circ} \mathrm{C}\right)$ for 50 minutes. Aliquots of the resulting cytosol fraction were taken for the determination of ODC, SAM-DC, and DNA polymerase and frozen at $-20^{\circ} \mathrm{C}$ until analysis. ODC and SAM-DC activities were analysed the same day.

Ornithine decarboxylase

ODC activity was calculated by measuring the picomoles of ${ }^{14} \mathrm{CO}_{2}$ liberated from the $1-{ }^{14} \mathrm{C}$ labelled substrate ornithine $(2.11 \mathrm{GBq} / \mathrm{mmol})$ as recently described in detail. ${ }^{23}$ Assays were run in triplicate and the results were calculated as picomoles ${ }^{14} \mathrm{CO}_{2} / \mathrm{h} / \mathrm{mg}$ DNA.

S-adenosylmethionine decarboxylase

SAM-DC activity was calculated by measuring the picomoles of ${ }^{14} \mathrm{CO}_{2}$ liberated from the substrate $S$-adenosyl-L-carboxyl- ${ }^{14} \mathrm{C}$-methionine (2.07 $\mathrm{GBq} / \mathrm{mmol})$ according to the method of Pegg and Pösö. ${ }^{24}$ Enzyme activity was expressed as picomoles ${ }^{14} \mathrm{CO}_{2} / 30 \mathrm{~min} / \mathrm{mg}$ DNA.

Spermidine/spermine N'-acetyltransferase

SAT activity was measured according to the method described by Matsui and colleagues ${ }^{25}$ by determining the formation rate of ${ }^{14} \mathrm{C}$ labelled $\mathrm{N}$-acetylspermidine from ${ }^{14} \mathrm{C}$-acetyl CoA $(2.07 \mathrm{GBq} / \mathrm{mmol})$ plus spermidine. SAT activity was calculated as picomoles N'acetylspermidine/min/mg DNA.

DNA polymerase

DNA polymerase activity was calculated as picomoles methyl- ${ }^{3} \mathrm{H}$-thymidine triphosphate (1.78 TBq/nmol) incorporated $/ 30 \mathrm{~min} / \mathrm{mg}$ DNA as described in detail by Haarstad et al. ${ }^{26}$ Methyl- ${ }^{3} \mathrm{H}$-thymidine 5-triphosphate (20 pmol) and $25 \mu \mathrm{g}$ activated calf thymus DNA were used as substrate. All assays were run in triplicate.

\section{Polyamines}

For polyamine separation an ion pairing reversed phase HPLC (Merck-Hitachi, Tokyo, Japan) method followed by postcolumn derivatisation with $o$-phthalaldehyde and consecutive fluorescence detection (F1000 fluorescence photometer) was used as previously published in detail. ${ }^{27}$ In contrast to the previously published method, the final dilution of pancreatic tissue for polyamine analysis was 1/10. Putrescine, spermidine, and spermine concentrations were calculated as nmol/mg DNA. 
DNA assay

DNA content was measured using the fluorescent dye $\mathrm{H}-33258$ according to the method of Labarca and Paigen. ${ }^{28}$ Calf thymus DNA was used as standard. DNA content was expressed as milligrams per total organ.

Protein

Protein content was determined according to the method of Bradford ${ }^{29}$ using bovine serum albumin as standard. Protein content was expressed as milligrams per total organ.

\section{STATISTICS}

Results were calculated as mean (SD) values. The between group statistical significances were evaluated by Student's $t$ test for unpaired values adapted for multivariate comparisons according to Holm. ${ }^{30}$

\section{Results}

Feeding of the PDD reduced alimentary polyamine intake by $98 \%(0.20 \mu \mathrm{mol} /$ day $)$. Average daily polyamine intake in PDD plus PA fed animals $(18.8 \mu \mathrm{mol} /$ day $)$ was similar to those fed with standard laboratory chow $(15.3 \mu \mathrm{mol} /$ day).

ANIMAL DEVELOPMENT

Food consumption and course of body weight during the 26 week feeding period revealed no significant differences between the four different treatment groups. Furthermore, no alterations in general animal behaviour or stool characteristics were observed during the half year feeding period. Long term feeding of all diets was well tolerated by the animals.

HISTOLOGICAL OBSERVATIONS

Tissue samples of small intestinal and colonic mucosa as well as the liver were taken from all animals after the 26 week feeding period for single blinded histological examination by a skilled pathologist. Apart from a slight hypotrophic appearance of small intestinal and colonic mucosa in PDD and PDD $+\mathrm{AB}$ fed rats no significant histopathological changes, and particularly no inflammation or necrosis, were observed in the organs of any diet fed group compared with standard laboratory chow fed controls.

TROPHIC PARAMETERS

Feeding of PDD $+\mathrm{AB}$ resulted in a significant $(p<0.005)$ decrease in wet organ weight in small intestine and colon, while feeding of PDD significantly $(p<0.01)$ decreased small intestinal mucosal weight (fig 1). Protein content of colonic mucosa and liver was not significantly different in the four treatment groups, but was significantly $(p<0.01)$ decreased in small intestinal mucosa of PDD fed animals compared with PDD + PA fed controls (fig 2). Feeding of PDD or PDD $+\mathrm{AB}$ resulted in a significant decrease in DNA content in small intestinal $(\mathrm{p}<0.01)$ and colonic $(\mathrm{p}<0.005)$ mucosa, while DNA content was not altered in the liver in any treatment group (fig 3). In the liver no significant alterations were found in any of the different treatment
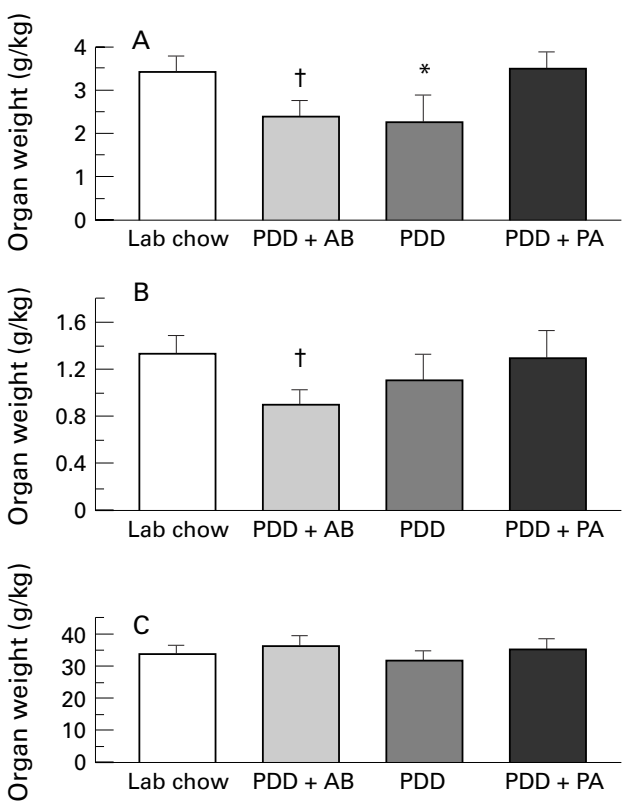

Figure 1 Organ weight of $(A)$ small intestinal mucosa, (B) colonic mucosa, and $(C)$ liver in rats $(n=7-10)$ after a 26 week feeding period with either $P D D, P D D+A B, P D D$ $+P A$, or standard laboratory chow. Significant differences versus $P D D+P A:{ }^{\star} p<0.01 ; t p<0.005$.
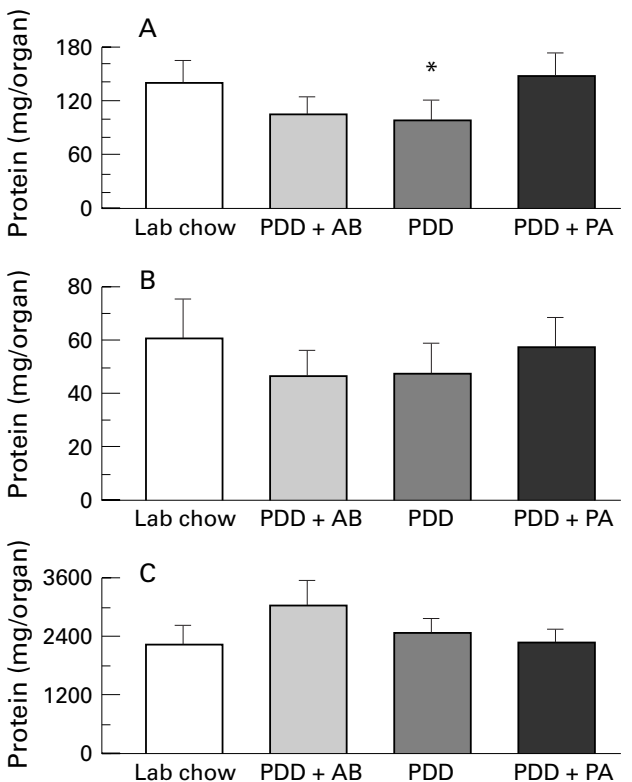

Figure 2 Protein content of $(A)$ small intestinal mucosa, (B) colonic mucosa, and $(C)$ liver in rats $(n=7-10)$ after a 26 week feeding period with either $P D D, P D D+A B, P D D$ $+P A$, or standard laboratory chow. Significant differences versus $P D D+P A:{ }^{\star} p<0.01$.

groups (figs 1, 2, and 3). DNA polymerase activity was not significantly altered in any of the three organs of the animals fed with the different diets (data not shown).

\section{POLYAMINE METABOLISM}

No significant changes in the activities of ODC, SAM-DC, or SAT, or concentrations of putrescine, spermidine, and spermine (data not shown) were observed in small intestinal mucosa, colonic mucosa, and liver between any of the four different treatment groups. 

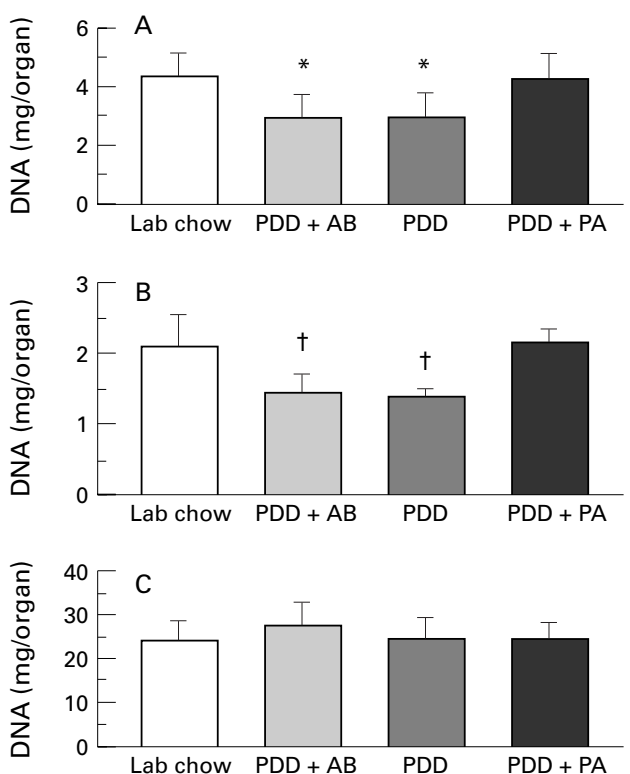

Figure $3 \mathrm{DNA}$ content of $(A)$ small intestinal mucosa, (B) colonic mucosa, and $(C)$ liver in rats $(n=7-10)$ after a 26 week feeding period with either PDD, $P D D+A B, P D D$ $+P A$, or standard laboratory chow. Significant differences versus $P D D+P A:{ }^{\star} p<0.01 ; t p<0.005$.

\section{Discussion}

Dietary and luminal gastrointestinal polyamines contribute significantly to the polyamine body pool ${ }^{163132}$ and are essentially involved in early small intestinal maturation and functional development, ${ }^{19-21}$ and stimulate intestinal growth and adaptation, ${ }^{11} 1215-183334$ as well as the proliferation of various malignant solid tumours..$^{8-10} 22$ Extending these observations, the results of the present long term study reveal that feeding of polyamine deficient diets induces significant hypoplasia of small intestinal and colonic mucosa. Our data prove the importance of dietary and luminal polyamines as local growth factors for mucosal nutrition and development even in normally growing animals.

The diets used in the present study were identically prepared as described by Sarhan and colleagues ${ }^{8}$ and Seiler et al. ${ }^{9}$ This balanced diet has a highly significantly reduced polyamine content and the long term results of the present six month study confirm previous short term observations ${ }^{8922}$ by showing that this diet was well tolerated by the animals, caused no obvious side effects, and no differences in food intake compared with animals fed with normal laboratory chow. Therefore, feeding of this diet proved to be an excellent experimental tool to evaluate the effects of dietary polyamine deprivation on various physiological and pathophysiological conditions in vivo.

Gut bacteria are known to produce considerable amounts of polyamines. There is also experimental evidence that polyamines derived from bacteria resident in the gut contribute to the body polyamine pool..$^{734}$ The amount of polyamines produced by gut bacteria is however not yet defined and their importance is controversial. Oral administration of metroni- dazole and neomycin almost completely eliminates Gram negative bacteria, while Gram positive bacteria are only reduced in number. ${ }^{8}$ Our data confirm and extend earlier observations by showing that even long term administration of both antibiotics over six months causes no significant side effects and is well tolerated by the animals. ${ }^{8922}$ Nevertheless, to what extent bacterial derived intraluminal polyamines are eliminated and whether there is any adaptation of the gastrointestinal flora during long term feeding of both antibiotics is not known and is difficult to verify experimentally. ${ }^{822}$ Simultaneous administration of these antibiotics resulted in no significant additional alterations to any of the trophic parameters measured compared with polyamine deficient diet fed animals. Therefore, the data of the present study do not suggest that bacterially derived polyamines are more important than those derived from the diet.

Deprivation of luminal polyamines resulted in a significant hypoplasia of small intestinal and colonic mucosa; however no significant alterations to the intracellular polyamine metabolism were observed in either organ compared with controls. The lack of significantly increased activities of ornithine decarboxylase and $S$-adenosylmethionine decarboxylase indicates that at least after a six month feeding period intracellular de novo synthesis is not activated as a compensatory mechanism to maintain intracellular polyamine homoeostasis in small intestinal and colonic mucosa. This is in accordance with observations in short term intestinal growth models where Bardòcz and colleagues $^{15} 1835$ showed that uptake of polyamines through the basolateral membrane is the important regulatory mechanism for maintenance of small intestinal polyamine concentrations during adaptive growth. Based on these observations, uptake of polyamines via the basolateral membrane is the best candidate for compensation and maintainenance of polyamine concentrations in the gastrointestinal mucosa in polyamine deficient chow fed animals. Nevertheless, the present data reveal that dietary polyamines are important local factors for small intestinal and colonic mucosal growth, irrespective of whether there was intracellular compensation of polyamine deficiency. The local mechanisms, however, are not yet known.

In conclusion, long term feeding of polyamine deficient diets resulted in a significant hypoplasia of small intestinal and colonic mucosa, while no effects were found in the liver. Dietary, luminal polyamines are important local growth factors for the nutrition and development of small intestinal and colonic mucosa in normally growing rats.

We acknowledge the expert technical assistance of Ms P Lüth and Ms F Grohmann. This study was kindly supported by generous grants of the Deutsche Forschungsgemeinschaft (DFG grant Lö 459/2-1) and the European Union (COST 917). Parts of the present investigation were presented at the 24th meeting of the European Pancreatic Club (EPC) in London, 9-12 July of the European Pancreatic Club (EP
1997 (Digestion 1997;58(suppl 2):57). 
1 Tabor CW, Tabor H. Polyamines. Anmu Rev Biochem 1984;53:749-90.

2 Pegg AE, McCann PP. Polyamine metabolism and function. Am f Physiol 1982;243:C212-21.

3 Pegg AE. Polyamine metabolism and its importance in neoplastic growth and as a target for chemotherapy. Cancer Res 1988;48:759-74

4 Seiler N. Polyamine metabolism. Digestion 1990;46(suppl 2):319-30.

5 Seiler N, Delcros JG, Moulinoux JP. Polyamine transport in mammalian cells. An update. Int F Biochem Cell Biol 1996; 28:843-61.

6 Seidel ER, Scemama JL. Gastrointestinal polyamines and regulation of mucosal growth and function. $\mathcal{F}$ Nutr Biochem 1997;8:104-11.

7 Hessels J, Kingma AW, Ferwerda H, et al. Microbial flora in the gastrointestinal tract abolishes cytostatic effects of $\alpha$-difluoromethylornithine in vivo. Int $f$ Cancer 1989;43: 1155-64.

8 Sarhan S, Knödgen B, Seiler N. The gastrointestinal tract as polyamine source for tumor growth. Anticancer Res 1989;9: 215-24.

9 Seiler N, Sarhan S, Grauffel C, et al. Endogenous and exogenous polyamines in support of tumor growth. Cancer Res 1990;50:5077-83.

10 Quemener V, Blanchard Y, Chamaillard L, et al. Polyamine deprivation: a new tool in cancer treatment. Anticancer Res 1994;14:443-8.

11 Luk GD. Polyamines in normal and adaptive gastrointestinal growth. In: Dowling RH, Fölsch UR, Löser C, eds, Polyamines in the gastrointestinal tract. Dordrecht: Kluwer Academic Publishers, 1992:205-16.

12 Dowling RH. Cellular and molecular basis of intestinal and pancreatic adaptation. Scand $\mathcal{F}$ Gastroenterol 1992;27(suppl 193):64-7

13 Kobayashi M, Iseki K, Saitoh $\mathrm{H}$, et al. Uptake characteristic of polyamines into rat intestinal brush-border membrane. of polyamines into rat in

14 Milovic V, Stein J, Piiper A, et al. Characterization of putrescine transport across the intestinal epithelium: study putrescine transport across the intestinal epithelium: study
using isolated brush border and basolateral membrane using isolated brush border and basolateral membrane
vesicles of the enterocyte. Eur 7 Clin Invest 1995;25:97105 .

15 Bardòcz S, Brown DS, Grant G, et al. Luminal and basolateral polyamine uptake by rat small intestine stimulated to grow by Phaseolus vulgaris lectin phytohaemagglutinin in vivo. $B B A$ 1990;1034:46-52

16 Bardòcz S, Duguid TJ, Brown DS, et al. The importance of dietary polyamines in cell regeneration and growth. $\mathrm{Br} f$ Nutr 1995;73:819-28.

17 Osborne DL, Seidel ER. Microflora-derived polyamines modulate obstruction-induced colonic mucosal hypertrophy. Am F Physiol 1989;19:G1049-57.

18 Bardòcz S, Grant G, Brown DS, et al. Polyamine metabolism and uptake during Phaseolus vulgaris lectin, PHA-induced growth of rat small intestine. Digestion 1990; 46:360-6.

19 Dufour C, Dandrifosse G, Forger P, et al. Spermine and spermidine induce intestinal maturation in the rat. Gastrospermidine induce intestinal

20 Buts JP, De Keyser N, Kolanowski J, et al. Maturation of villus and crypt cell functions in rat small intestine. Role of dietary polyamines. Dig Dis Sci 1993;38:1091-8.
21 Kaouass M, Deloyer P, Wery I, et al. Analysis of structural and biochemical events occurring in the small intestine after dietary polyamine ingestion in suckling rats. Dig Dis Sci 1996;41:1434-44.

22 Sarhan S, Knödgen B, Seiler N. Polyamine deprivation, malnutrition and tumor growth. Anticancer Res 1992;12: $457-66$.

23 Löser C, Fölsch UR, Cleffmann U, et al. Role of ornithine decarboxylase and polyamines in camostate (FOY 305)induced pancreatic growth in rats. Digestion 1989;43:98112.

24 Löser C, Fitting T, Fölsch UR. Importance of intracellular S-adenosylmethionine decarboxylase activity for the regulation of camostate-induced pancreatic polyamine metabolism and growth: in vivo effect of two novel S-adenosylmethionine decarboxylase inhibitors. Digestion 1997;58:258-65.

25 Matsui I, Wiegand L, Pegg AE. Properties of spermidine $\mathrm{N}$-acetyltransferase from liver of rats treated with carbon tetrachloride and its role in the conversion of spermidine into putrescine. F Biol Chem 1981;256:2454-9.

26 Haarstad H, Winnberg A, Petersen H. Effects of a cholecystokinin-like peptide on DNA and polyamine synthesis in the rat pancreas. Scand f Gastroenterol 1985;20: 530-8.

27 Löser C, Wunderlich U, Fölsch UR. Reversed-phase liquid chromatographic separation and simultaneous fluorimetric detection of polyamines and their monoacetyl derivatives in human and animal urine, serum and tissue samples: an improved, rapid and sensitive method for routine application. F Chromatogr 1988;430:249-62.

28 Labarca C, Paigen K. A simple, rapid and sensitive DNA assay procedure. Anal Biochem 1980;102:344-52.

29 Bradford MM. A rapid and sensitive method for the quantitation of microgram quantities of protein utilizing the principle of protein-dye binding. Anal Biochem 1976;72:24855 .

30 Holm A. A single sequentially rejective multiple test procedure. Scand F Stat 1970;6:65-70.

31 Löser C, Torff L, Fölsch UR. Uptake of extracellular, dietary putrescine is an important regulatory mechanism of intracellular polyamine metabolism during camostateinduced pancreatic growth in rats. Dig Dis Sci 1997;42: 503-13

32 Dorhout B, van Faassen A, van Beusekom CM, et al. Oral administration of deuterium-labelled polyamines to sucking rat pups: luminal uptake of, metabolic fate and effects on gastrointestinal maturation. Br F Nutr 1997;78: 639-54.

33 Dowling RH. Polyamines in intestinal adaptation and disease. Digestion 1990;46(suppl 2):331-44.

34 Osborne DL, Seidel ER. Gastrointestinal luminal polyamines: cellular accumulation and enterohepatic circulation. Am f Physiol 1990;258:G576-84.

35 Bardòcz S. The role of basolateral polyamine uptake in intestinal adaptation. In: Dowling RH, Fölsch UR, Löser $\mathrm{C}$, eds, Polyamines in the gastrointestinal tract. Dordrecht: Kluwer Academic Publishers, 1992:409-16. 